\title{
Evaluation of Image Reconstruction Using Binary Genetic Algorithm and Unwrapping in Digital Holography
}

\author{
Tuğba Özge ONUR ${ }^{1 a^{*}}$, Gülhan USTABAŞ KAYA $^{1 \mathrm{~b}}$ \\ ${ }^{1}$ Department of Electrical-Electronics Engineering, Zongudak Bulent Ecevit University, Zonguldak, Turkey \\ tozge.ozdinc@beun.edu.tr
}

Received/Geliş: 25.04 .2021

Accepted/Kabul: 08.07.2021

\begin{abstract}
Image reconstruction is a fundamental task of image processing and images are desired to be reconstructed with the lowest noise and most accuracy possible. Digital holography is one of the image reconstruction methods that uses Fast Fourier Transform (FFT) as a common tool. However, several iterative methods such as genetic algorithm (GA) can be used to decrease the noise or optimize the digital hologram in the reconstruction process for digital holography. In this paper, we propose an image reconstruction task that is performed by using a binary genetic algorithm (BGA) in digital holography. In this scheme, the image of a glassmade star object is reconstructed both originally and also by using BGA to find a similar solution to the originally reconstructed one. The unwrapping effect in the reconstructed image is also evaluated by using two different methods that are Goldenstein's and Quality guided path-following techniques. The results indicate that since BGA provides a solution with higher similarity to the originally reconstructed one, it can be considered as an alternative to the common reconstruction process in digital holography. Besides, since a 3-dimensional (3D) image with phase information is obtained by unwrapping techniques, it provides to have better quality images.
\end{abstract}

Keywords: Digital holography; image reconstruction; binary genetic algorithm; unwrapping.

\section{Sayısal Holografide İkili Kodlu Genetik Algoritma ve Faz Düzeltme Kullanarak Görüntünün Yeniden Oluşturulmasının İncelenmesi}

\begin{abstract}
Öz: Görüntü işlemede, görüntünün yeniden oluşturulması temel bir işlemdir ve görüntülerin mümkün olan en düşük gürülttü ve en yüksek doğrulukla yeniden oluşturulması istenir. Sayısal holografi, yaygın olarak Hızlı Fourier Dönüşümünü (FFT) kullanan görüntü yeniden oluşturma yöntemlerinden biridir. Ancak, sayısal holografinin yeniden oluşturma sürecinde gürülttüyü azaltmak veya sayısal hologramı optimize etmek için genetik algoritma (GA) gibi çeşitli yinelemeli yöntemler kullanılabilir. Bu çalışmada, sayısal holografide ikili kodlu genetik algoritma (BGA) kullanılarak gerçekleştirilen bir görüntü yeniden oluşturma sunulmaktadır. $\mathrm{Bu}$ amaçla, camdan yapılmış bir yıldız nesnenin görüntüsü hem orjinal olarak hem de orijinal olarak yeniden yapılandırılana benzer bir çözüm bulmak için BGA kullanılarak yeniden oluşturulmaktadır. Ayrıca yeniden oluşturulan görüntüdeki faz düzeltme etkisi Goldenstein ve Quality guided path teknikleri olmak üzere iki farklı yöntem kullanılarak değerlendirilmektedir. Elde edilen sonuçlar, BGA'nın orijinal olarak yeniden oluşturulan görüntüye oldukça benzer bir çözüm sağladığından, sayısal holografide yaygın olarak kullanılan yeniden oluşturma işlemine bir alternatif olarak düşünülebileceğini göstermektedir. Ayrıca, faz bilgisine sahip 3-boyutlu (3B) görüntü, faz düzeltme teknikleri ile elde edildiğinden, daha kaliteli görüntülere sahip olunmasını sağlar.
\end{abstract}

Anahtar Kelimeler: Sayısal holografi; görüntü yeniden oluşturma; ikili kodlu genetik algoritma; faz düzeltme.

\section{Introduction}

The spectral, directional, and spatial information about a specimen is desired to be captured with imaging systems. While a digital image is acquired, it can be distorted optically or electronically.

Onur, T. Ö. and Ustabaș Kaya, G, "Evaluation of Image Reconstruction Using Binary Genetic Algorithm and Unwrapping in Digital Holography" El-Cezerî Journal of Science and Engineering, 2021, 8 (3); 1338-1350. 
Therefore, it is important to obtain a clear and high-resolution image of the original one to provide a correct understanding by humans. To transform the acquired raw data (recorded specimen) to images, image reconstruction, which is a fundamental branch in the field of image processing, should be applied [1]. The image quality can be impacted by multiple signal processing in the image reconstruction process. There have been various methods used for image reconstruction applications in the current literature. Digital holography is one of the most used methods for numerical image reconstruction [2]. In this method, the intensity pattern of spatial interference between the light scattered from the sample is recorded by detectors and then both phase and amplitude contrast images of the specimen are acquired by using a numerical reconstruction algorithm. Fast Fourier Transform (FFT) is a commonly used tool for direct image reconstruction in digital holography [1]. On the other hand, Kugler et al. propose a non-rigid three-dimensional (3D) reconstruction method. The smoothness and continuity are required for internal structures, which are located on the main tissue when the reconstruction process is performed [3]. Kawamura et al. used a landmark-based method for the 3D image reconstruction. They use a template matching to detect the landmarks, which is corresponded to the used images. After this step, the detected landmarks are located in the reconstructed 3D image, which has a single smooth curve. Thus the deformations of all used images are determined simultaneously [4]. Rusdi et al. reconstruct the medical images with an artificial bee colony algorithm. They assess the efficiency of this algorithm with the optimal solution to the problem of curve fitting [5].

In recent years, genetic algorithms (GA) have been applied for image reconstruction in addition to the fields of economics, chemistry, physics, computer science, engineering applications, etc. In recent studies, especially for the task of medical image reconstruction, GA is used to provide an optimum solution [6,7]. A typical GA begins with the population of potential solutions that are called chromosomes or individuals. These are generated randomly. Generally, binary strings are used to represent the chromosomes. It is aimed to obtain the best solution which provides the higher similarity to the reconstructed one by improving with initial images. In this context, an algorithm of the local search for multi-objective genetics is introduced by Li et al. for projections-based image reconstruction. This work remains weak in terms of the weight parameters that depend on the subjective choice [8]. Qureshi et al. proposed a genetic algorithm related to hybrid continuous, which is hybridized with inverse Fourier transform, to solve the image reconstruction problem [9]. Majeed and Piah used the rational Ball interpolant via GA to reconstruct the different images. They optimized the unknown parameters by using a genetic algorithm [10]. Gray et al. performed a data exploration that uses a cooperative co-evolution algorithm as the base for PET image reconstruction. The used algorithm is called as Fly Algorithm [11].

On the other hand, in many images or signal applications, phase is an important feature to detect the object's deformation, shape, or vibration. To increase the image quality of reconstructed images and analyze the real data successfully, phase unwrapping techniques can be used for many applications such as interferometry imaging, solid-state physics, etc. [12,13]. The required data can be encoded in the phase distribution form by using unwrapping for phase information [14]. Especially, in optical interferometry imaging, 2-dimensional (2D) phase unwrapping is also used to solve many problems [15]. Therefore, various unwrapping algorithms have been proposed in the literature [16]. The used standard algorithms for implementing the phase unwrapping application often fail to image at low light intensities for interferometric quantitative phase imaging. For this reason, Kim et al. used an analysis method of Hybrid random walk-linear discriminant to unwrap the quantitative phase images. They also applied this method for imaging biological samples [17]. Zappa and Busca used eight unwrapping algorithms to compare the performances of these algorithms, which are applied to the Fourier transform profilometry optical scan method [18]. Moreover, to perform the 2D MRI phase unwrapping, He et al. proposed an algorithm of SparseRepresentation-Based Direct Minimum Lp-Norm [19]. 
Motivated by the advances in digital holographic imaging, in this paper, we propose applying the unwrapping algorithms to binary image reconstruction using GA and comparing the effects on the reconstruction quality. In addition, an image reconstruction application is performed for the used black and white images using binary coding.

The rest of this paper is organized as follows. Genetic algorithm-based image reconstruction is detailed in Section 2. In Section 3, the unwrapping problem and unwrapping methods that are used in this study are explained. Section 4 is devoted to describing the scanning system used. Section 5 expresses the results whereas the last Section draws out the conclusions.

\section{Experimental Methods}

\subsection{Image Reconstruction Based on GA}

The genetic algorithm determines the maximum/minimum of some objective functions in a search space by mimicking natural selection and discovers all regions of the space by mutation, crossover, and selection operations [20]. Thereafter, successive generations are obtained by applying these operators to the populations. Generally, the search for an optimal solution is started with a randomly generated chromosome population. A new set of chromosomes is derived for each generation from the applications of the operators. The determination of the chromosomes representation, selection function, initial population creation, genetic operators, fitness function and termination criteria are the necessary issues for the use of a genetic algorithm and the following steps are applied with genetic algorithms [21]:

1. Initial population is produced.

2. Fitness of each individual is evaluated.

3. Fittest individual is selected for mating.

4. Reproductive operators are applied to create offspring.

5. The fitness of offspring is evaluated and fit individuals are selected.

6. It is stopped if the stopping criteria are met otherwise step 3 is repeated.

The basic steps for the use of a GA are depicted in Figure 1.

In this paper, a genetic algorithm representation of the solution domain for black-and-white images is investigated. For this case, each chromosome has genes like the pixels of the original image. Each gene can have the value 0 and 1 for white and black colors, respectively. After this issue, a fitness function that measures the quality of the obtained solution is formulated. Mean absolute error (MAE) fitness function is used to reconstruct the image in this paper which is defined as in Equation 1,

$$
F=\left(1+E_{M}\right)^{-1}
$$

where EM is the MAE value between the reference or measured image and computed reconstructions [6].

After the determination of genetic representation and the fitness function, a randomly initializing of the population is proceed by GA. Then, selection, crossover, and mutation steps proceed. In this paper, roulette wheel selection and double-point crossover are used. Natural selection is simulated by the selection operator and the roulette wheel enables the selection of individuals with higher fitness values [6]. By using double-point crossover, genes are exchanged between individuals that 
enable new solutions to be produced. The mutation which is the last one is performed in a common manner [22].

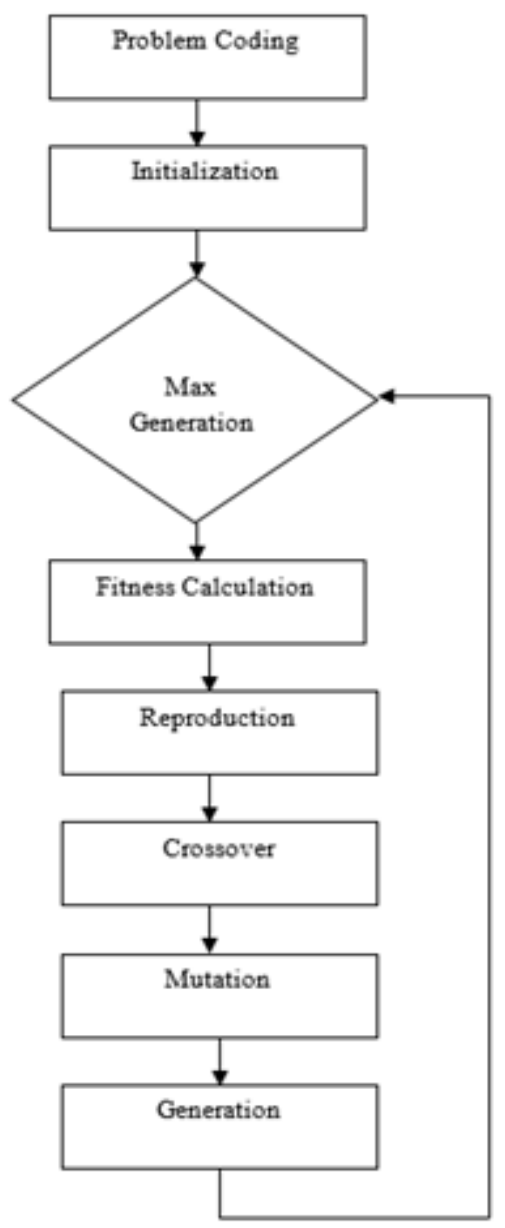

Figure 1. Basic steps for a genetic algorithm.

\subsection{Unwrap}

The wrapped phase is normally measured between $-\pi$ and $\pi$. However, the required information, which is used in various advanced imaging technologies, is encoded in the form of a phase distribution [23]. In this context, the principal phase values can be found with the phase unwrapping process, which is the most used algorithm in several applications such as optical interferometry imaging, imaging of medical magnetic resonance, etc. Many pieces of research have been studied for phase unwrapping techniques, which are the tasks of determining the accurate values of phase $[17,18,24]$. These algorithms can be considered in two classes such as path following (PF) and minimum norm methods. In PF methods, a path is defined for following the phase gradient integration and in minimum norm methods, the difference between the wrapped and unwrapped phase differences are minimized [25].

In this paper, the performances of Goldstein and Quality guided path-following methods that belong to the path following methods are investigated in the binary digital holographic images reconstructed with a genetic algorithm.

\subsubsection{Goldstein's Algorithm}

In Goldstein's algorithm, branch cuts (BC) are generated to constitute a barrier for the unwrapping process. The cuts are chosen for minimizing the sum of the lengths of $\mathrm{BC}$ and thus the total 
discontinuity [26]. The $\mathrm{BC}$ is connected with the residues being pairs or multiple pairs groups with the logic in the phase image. The BC is adjusted between the closest image border and the residue, which has no connection with other residues. The process steps of Goldstein's algorithm are given as follows [27]:

1. A branch point is found. $2 \times 2$ loop array is adjusted each time until finding a BC point.

2. After finding one $B C$ point, the top-left sample of the $2 \times 2$ loop is defined and a $3 \times 3$ pixel box is centered on this point.

3. To create different branch points, the centered $3 \times 3$ pixel box is found.

4. The size of this box is extended if the branch points are not found. On the contrary, the two branch points are connected and marked as balanced. Namely, in the Goldstein method, the restriction lines are added to the path of the phase map and the poles have potential equilibrium.

5. Finally, the branch points are connected with an aperture edge.

\subsubsection{Quality Guided Path Following Method}

Since the Quality-guided phase unwrapping (QGPU) technique is an efficient, fast, and automatic spatial method, it has been well studied in the past two decades [16]. In spatial phase unwrapping, the unwrapping of one pixel can be performed with the equation given in Equation 2 [12].

$$
\varphi_{a}^{u}=\varphi_{a}^{w}+2 \pi x \text { round }\left(\frac{\varphi_{b}^{u}-\varphi_{a}^{w}}{2 \pi}\right)
$$

where the round is the function that converts the input to the closest integer; $\varphi_{b}^{u}, \varphi_{a}^{w}$ and $\varphi_{a}^{u}$ are the unwrapped phase of pixel $b$, wrapped and unwrapped phases of pixel $a$, respectively.

\subsection{Imaging Setup}

The proposed setup for imaging is shown in Figure 2 [28]. This setup is based on lateral shearing digital holographic microscopy, which is derived from the configuration of self-referencing. In this configuration, a He-Lazer is used as a light source and it has a $632 \mathrm{~nm}$ wavelength with the $12 \mathrm{~mW}$ output power. Firstly, a spatial filter is used to filter the beam, and then it is aligned with a convex lens (CL).

The object wavefront is magnified with a microscopic objective having a $6 \mathrm{X}$ magnification and 0.75 numerical aperture $(\mathrm{NA}=0.75)$. The plane ruled reflection grating (PRRG) glass plate, which has $6 \mathrm{~mm}$ thickness, is preferred to create an interference pattern on the CMOS camera. The CMOS camera is kept from $10 \mathrm{~cm}$ from the PRRG glass plate. The shear glass plate has back and front surfaces to form two sheared object beams. These beams form the interference pattern. To cope with the image duplication and overlapping of object information problems, the second lens is located between the microscopic objective and the CMOS camera. In addition, the (approx.) whole field of view (FOV) is used to avoid the object information overlap. This means that the lateral shear distance is equated to the FOV value to get a fringe pattern having two-beam interference patterns digital holographic microscopy.

\section{Results and Discussion}

The experiments are conducted by using the image of a glass-made star object. Simulations are performed on MATLAB 2018b program to evaluate the effects of unwrapping and binary genetic 
algorithm in digital holographic image reconstruction. 100 chromosomes and 1000, 2000, 3000, 4000, 5000, 10000 generations are used for BGA respectively.

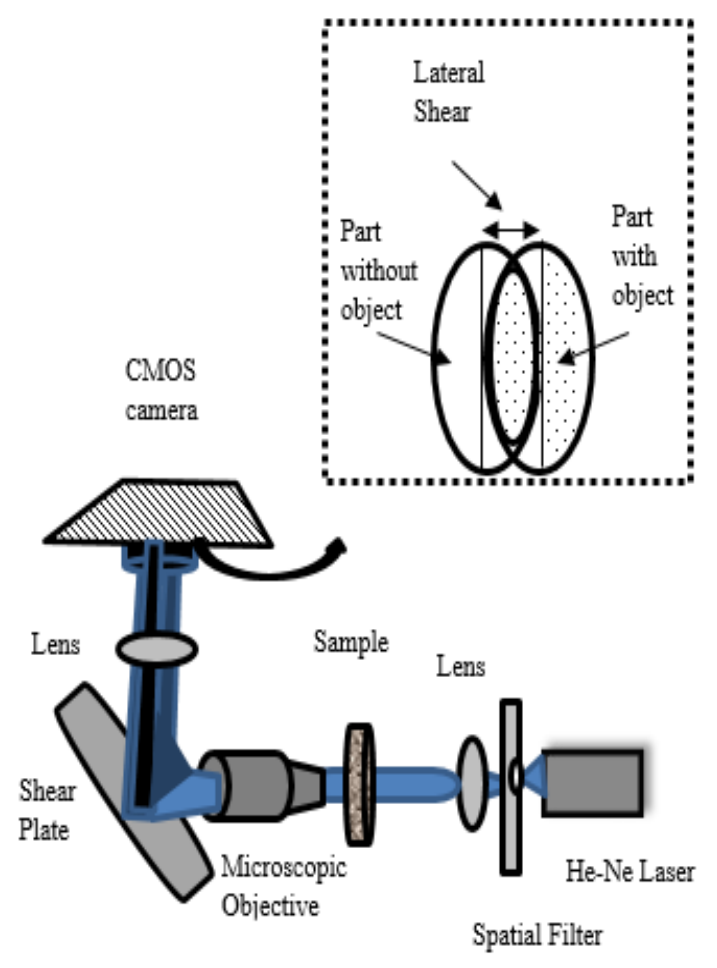

Figure 2. Imaging setup.

The values for probability crossover are given as 0.95 , the probability of mutation is used as 0.001 and the elitism rate is given as $20 \%$. The algorithm has stopped when the maximum number of iterations has been reached. The original reconstructed star image and the one obtained by using binary image reconstruction using BGA are shown in Figure 3. The simulation has been based on $1000,2000,3000,4000,5000,10000$ repetitions for 256x256 star image respectively. It can be easily seen from Figure 3 that crossover and mutation operators provide the best fit to the reconstruction of a digital holographic image and binarized reconstructed star image can be obtained with 10000 epochs. In addition, the reconstructed image by using BGA has almost the same details as the original reconstructed one. Figure 4 shows the fitness graphs of each epoch and the fitness of the best elite that provides to reach the optimal solution is obtained with 10000 epochs. Moreover, to evaluate the effect of phase unwrapping to the digital holographic image reconstruction by using BGA, Goldenstein's and QGPU techniques are applied. Since both the amplitude information and phase information characterize the beam and only the values of signal that are between $-\pi$ and $+\pi$ radians are influenced by the phase, obtaining true phase can enable to reveal the details or properties of the object. Besides, phase unwrapping provides not only a $2 \mathrm{D}$ image of the object but a 3D image with phase information. Figure 5 indicates the results for original and BGA image reconstruction by using Goldenstein's algorithm. It can be seen from Figure 5 that a 3D reconstructed image is obtained with both original and BGA image reconstruction in the case of Goldstein's unwrapping technique is applied. However, in addition, it can be seen from Figure 5 and also Figure 6 that shows the corresponding fitness graphs of each epoch for BGA, unwrapping is sensitive to noise. Therefore, worse the fitness of the best elite at 10000 epoch is obtained when compared with the wrapped BGA reconstructed image given in Figure 4. Figure 7 shows the obtained star images with the QGPU technique for both original and BGA reconstructed images. Likewise, the noise effect can be seen easily from both Figure 7 and corresponding fitness graphs for BGA in Figure 8. In addition, it can also be observed that noise 
appears to be more effective compared to Goldstein's unwrapping algorithm. Table 1 indicates the best fitness value of each situation for each epoch.

The quality of the binarized and unwrapped binarized reconstructed images has been measured utilizing mean squared error (MSE), mean absolute error (MAE), and structural similarity measure (SSIM) of the reconstructed image. MSE gives the measurement for the average of the squares of the errors and closer to zero results for this metric is better. Since MAE defines the maximum absolute value of the variance (difference) between the original reconstructed and BGA or unwrapped ones, closer to zero values are better, too. In terms of SSIM, a better result is obtained when it is closer to 1. The mathematical expressions of MSE, MAE, and SSIM are given in Equations 3-5, respectively [29]. Table 2 and Table 3 show the values of quality metrics between the reconstructed image and binarized reconstructed star image and reconstructed image and binarized reconstructed unwrapped star image with Goldstein's and QGPU techniques, respectively.

$$
\begin{aligned}
& M S E=\frac{1}{M N} \sum_{i=1}^{M} \sum_{j=1}^{N}(x(i, j)-y(i, j))^{2} \\
& M A E=\frac{1}{M N} \sum_{i=1}^{M} \sum_{j=1}^{N}|x(i, j)-(i, j)| \\
& \operatorname{SSIM}=\frac{\left(2 \bar{x} \bar{y}+C_{1}\left(2 \sigma_{x y}+C_{2}\right)\right)}{\left(\sigma_{x}^{2}+\sigma_{y}^{2}+C_{2}\right)\left((\bar{x})^{2}+(\bar{y})^{2}+C_{1}\right)}
\end{aligned}
$$

where $\mathrm{M}$ and $\mathrm{N}$ are the pixel motions of the image and the parameters of this expression are given with (i,j); $C_{1}$ and $C_{2}$ are constants; $\sigma_{x}^{2}$ and $\sigma_{y}^{2}$ are the correlation coefficients of $\mathrm{x}$ and $\mathrm{y}$, respectively.

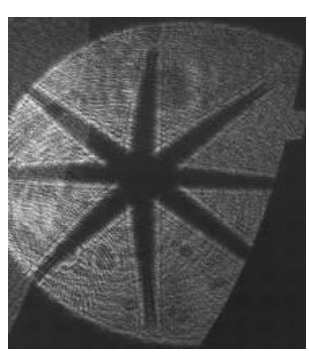

(a) Original wrapped reconstructed star image

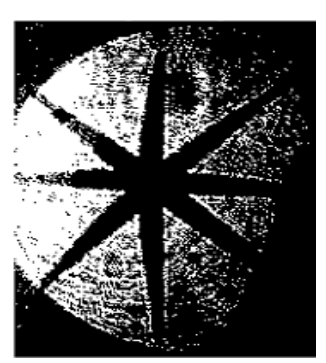

(b) Wrapped binarized reconstructed star image

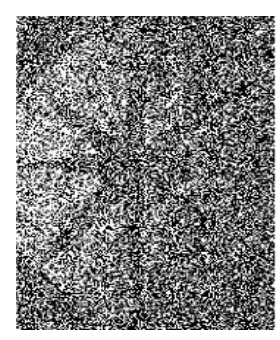

(c) 1000 epoch

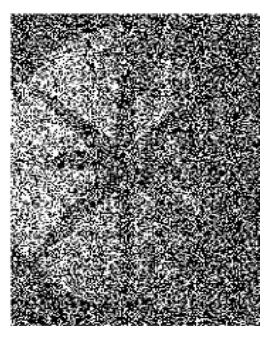

(d) 2000 epoch

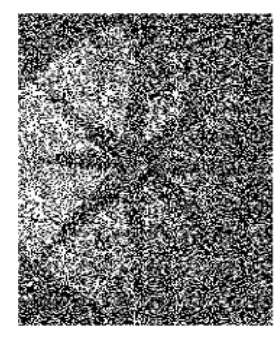

(e) 3000 epoch

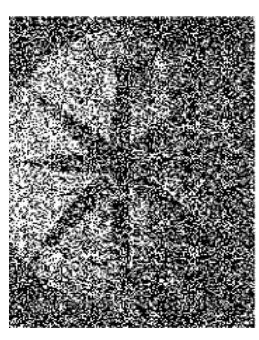

(f) 4000 epoch

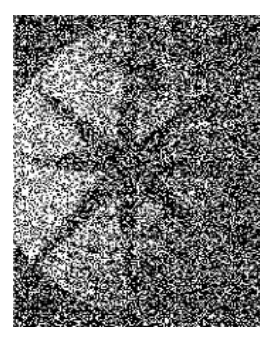

(g) 5000 epoch

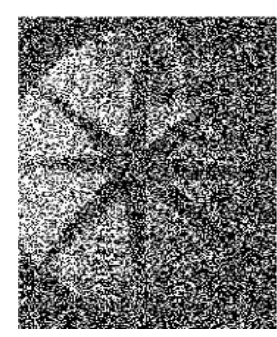

(h) 10000 epoch

Figure 3. The obtained star images without unwrap techniques. 


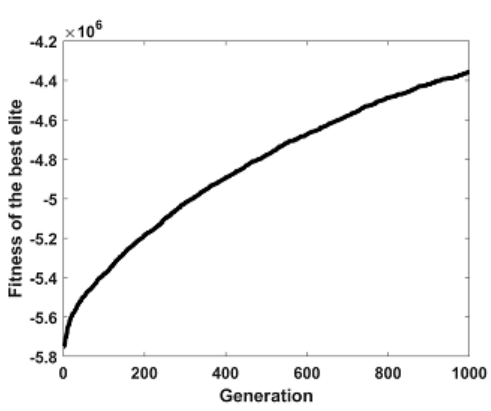

(a) 1000 epoch

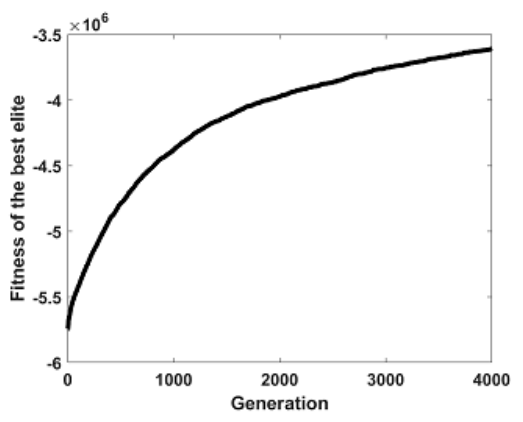

(d) 4000 epoch

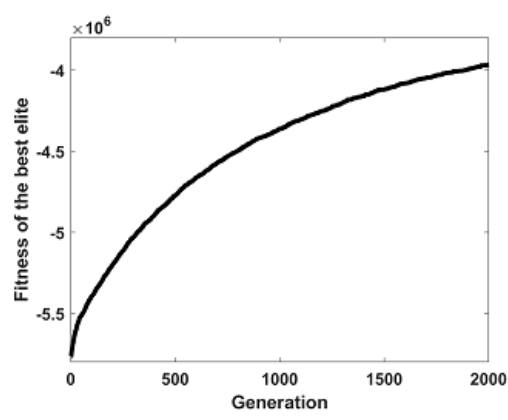

(b) 2000 epoch

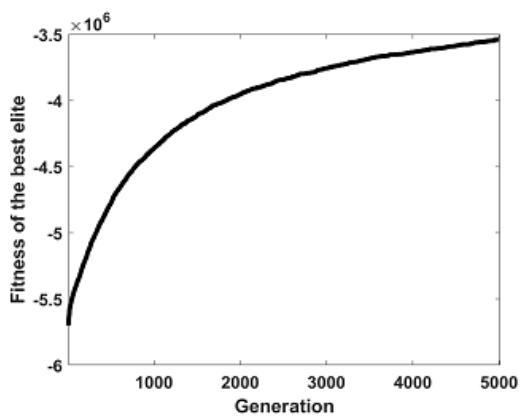

(e) 5000 epoch

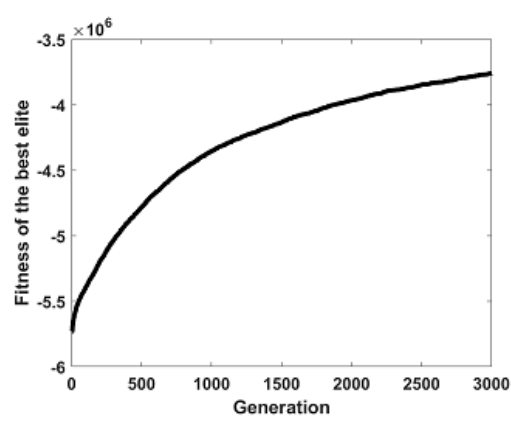

(c) 3000 epoch

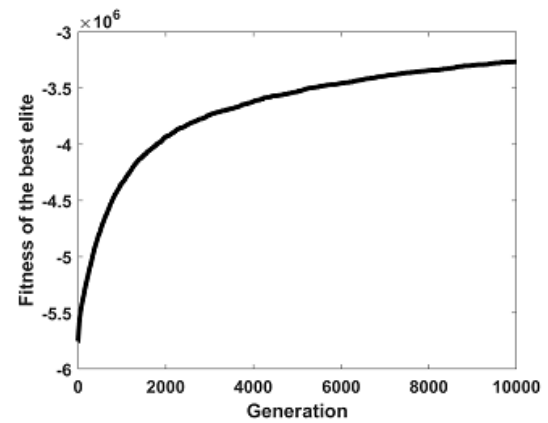

(f) 10000 epoch

Figure 4. The obtained fitness graphs for star images without unwrap techniques.

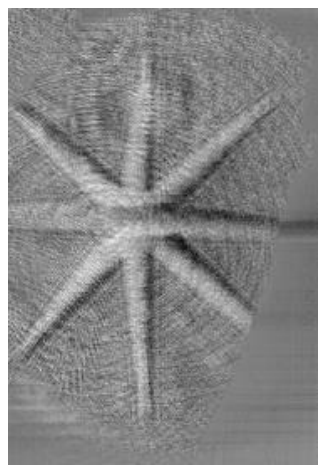

(a) Original unwrapped reconstructed star image

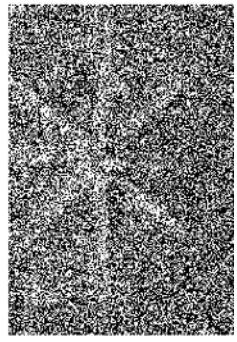

(c) 1000 epoch

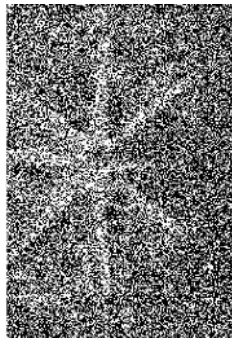

(d) 2000 epoch

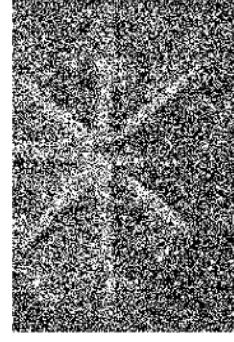

(e) 3000 epoch

(b) Unwrapped binarized reconstructed star image

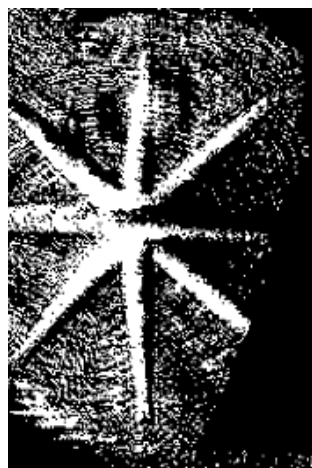

Figure 5. The obtained star images with Goldstein's unwrap technique. 


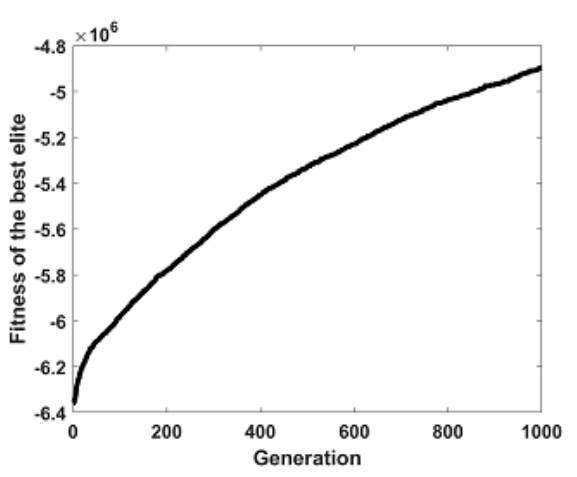

(a) 1000 epoch

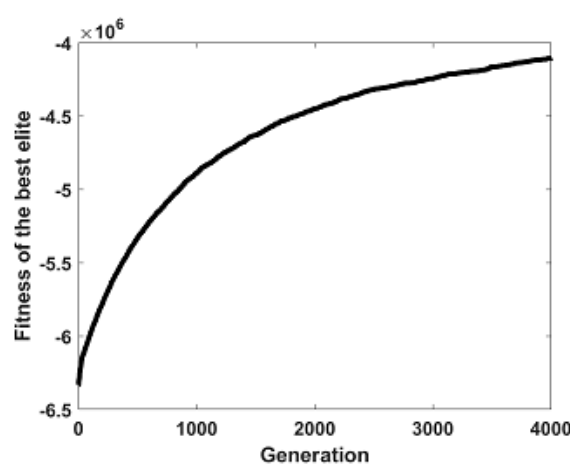

(d) 4000 epoch

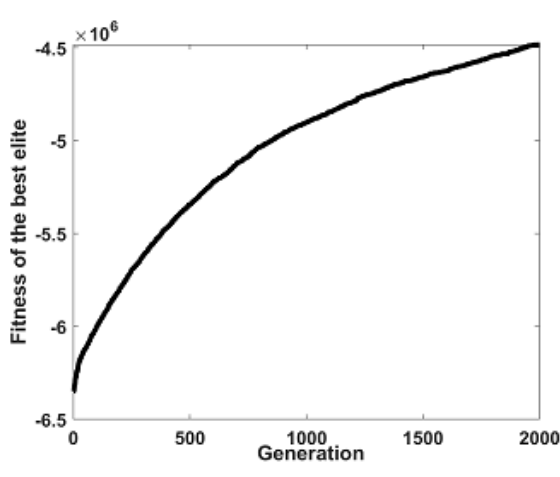

(b) 2000 epoch

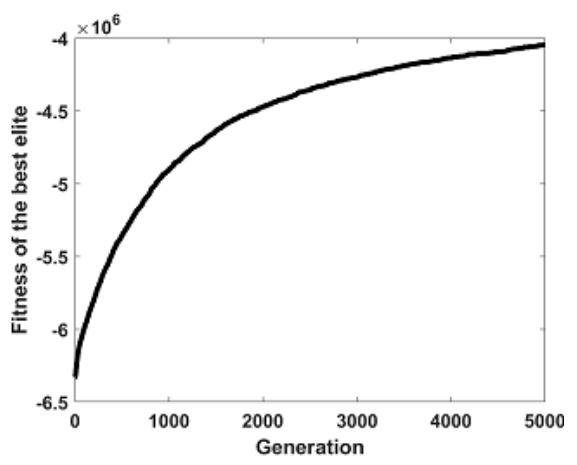

(e) 5000 epoch

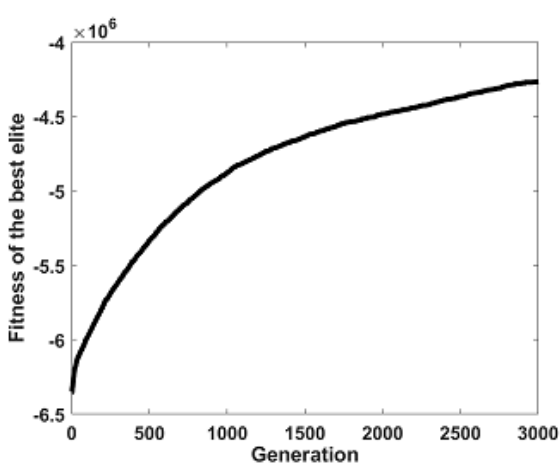

(c) 3000 epoch

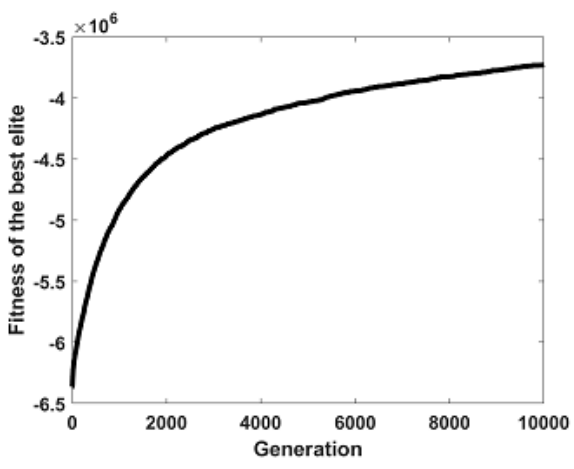

(f) 10000 epoch

Figure 6. The obtained fitness graphs for star images with Goldstein's unwrap technique.

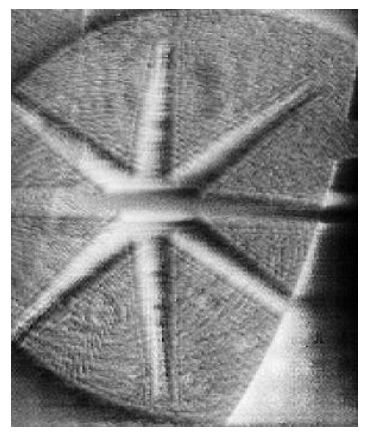

(a) Original unwrapped reconstructed star image

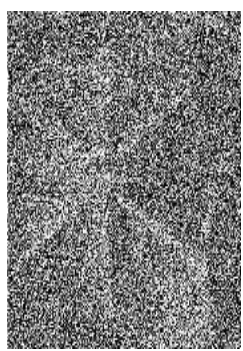

(c) 1000 epoch

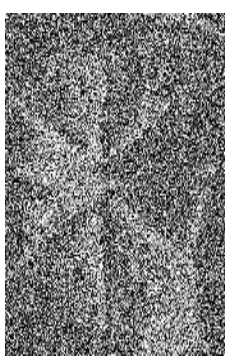

(d) 2000 epoch

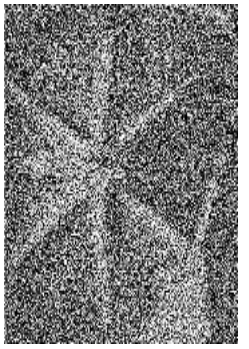

(e) 3000 epoch

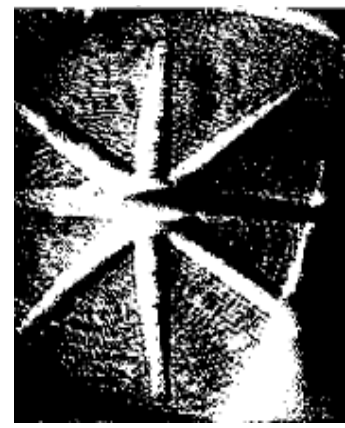

(b) Unwrapped binarized reconstructed star image

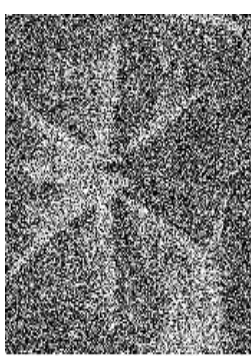

(f) 4000 epoch

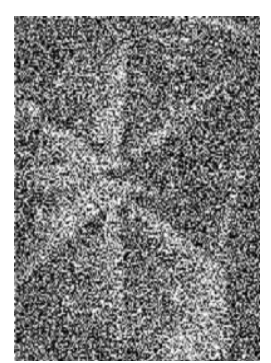

(g) 5000 epoch

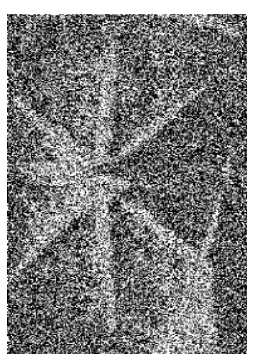

(h) 10000 epoch

Figure 7. The obtained star images with QGPU technique. 


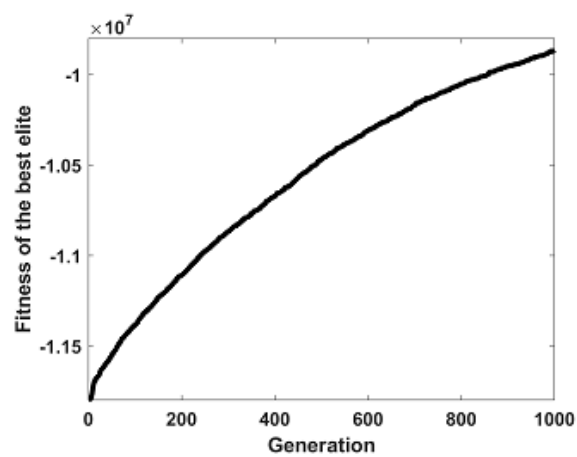

(a) 1000 epoch

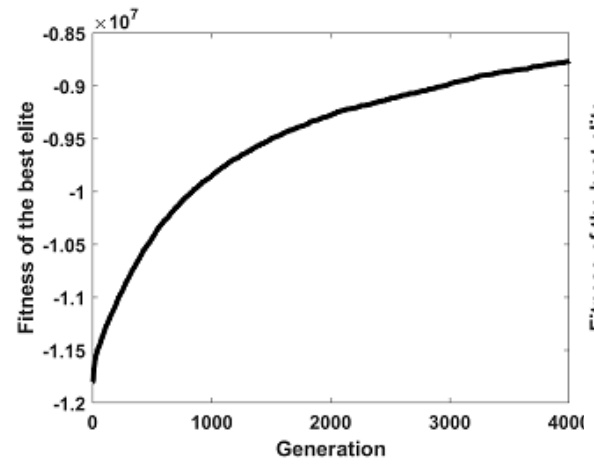

(d) 4000 epoch

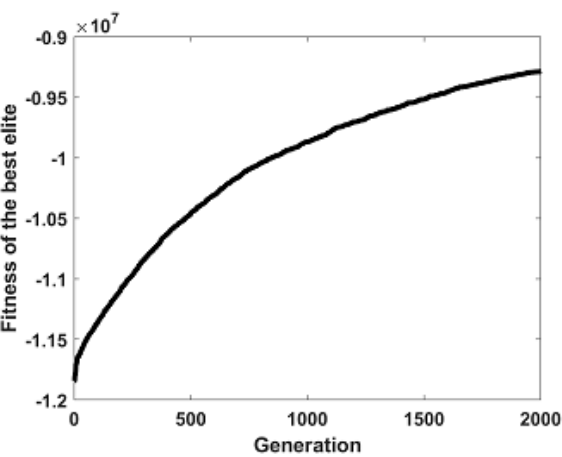

(b) 2000 epoch

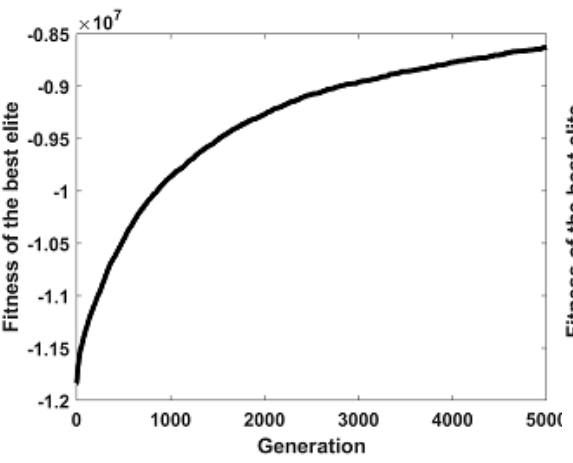

(e) 5000 epoch

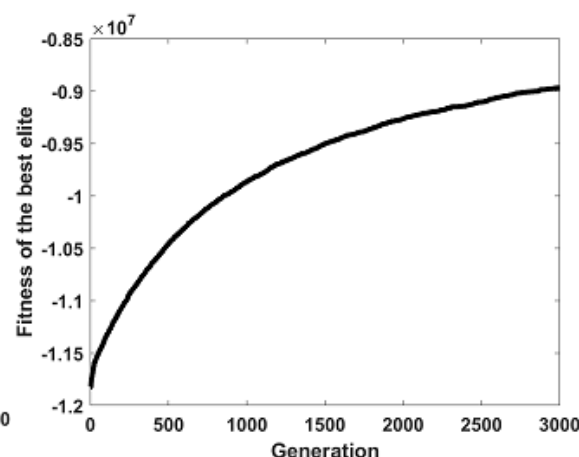

(c) 3000 epoch

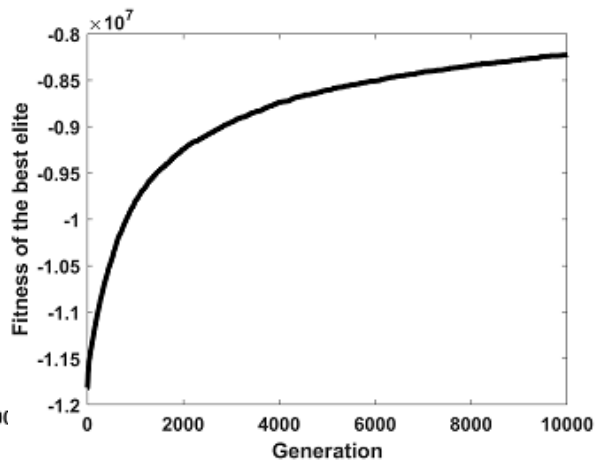

(f) 10000 epoch

Figure 8. The obtained fitness graphs for star images with QGPU technique.

Table 1. The best fitness values.

\begin{tabular}{|c|c|c|c|}
\hline & $\begin{array}{l}\text { Without Unwrap } \\
\text { Technique }\end{array}$ & $\begin{array}{l}\text { With Goldstein's } \\
\text { Unwrap Technique }\end{array}$ & $\begin{array}{c}\text { With QGPU } \\
\text { Technique }\end{array}$ \\
\hline 1000 epoch & -4357695 & -4894980 & -9867225 \\
\hline 2000 epoch & -3966525 & -4475505 & -9285060 \\
\hline 3000 epoch & -3759465 & -4265130 & -8968860 \\
\hline 4000 epoch & -3610035 & -4103970 & -8768685 \\
\hline 5000 epoch & -3539910 & -4046595 & -8631750 \\
\hline 10000 epoch & -3475395 & -3729630 & -8227320 \\
\hline
\end{tabular}

The obtained values of MAE, MSE, and SSIM metrics between the reconstructed and binarized reconstructed star image are given in Table 2. The values are presented for each epoch. Since MAE and MSE are the maximum absolute and mean squared error values of the difference between the reconstructed image and binarized reconstructed one respectively, closer to zero values are better for these metrics. On the other hand, a better result is obtained when it is closer to 1 in terms of SSIM. By considering these metrics, it can be seen in Table 2 that better matching is provided with minimum MAE and MSE and maximum SSIM values at 10000 epoch. 
Table 2. The values of quality metrics between the reconstructed image and binarized reconstructed star image.

\begin{tabular}{cccc}
\hline \multicolumn{4}{c}{ The Difference Between Reconstructed and } \\
\hline Number of Epochs & MAE & MSE & SSIM \\
\hline $\mathbf{1 0 0 0}$ epochs & 0.0903 & 0.0374 & 0.0432 \\
$\mathbf{2 0 0 0}$ epochs & 0.0861 & 0.0347 & 0.0566 \\
$\mathbf{3 0 0 0}$ epochs & 0.0835 & 0.0330 & 0.0622 \\
$\mathbf{4 0 0 0}$ epochs & 0.0817 & 0.0318 & 0.0765 \\
$\mathbf{5 0 0 0}$ epochs & 0.0815 & 0.0317 & 0.0744 \\
$\mathbf{1 0 0 0 0}$ epochs & 0.0812 & 0.0317 & 0.0820
\end{tabular}

Table 3 shows the obtained values of MAE, MSE, and SSIM metrics between the reconstructed and binarized reconstructed star image when unwrapping techniques are used. It can be easily seen that the obtained results are getting better in terms of all metrics compared to wrapped ones given in Table 2. In addition to this, a better SSIM value is obtained when Goldstein's technique is used since the QGPU technique is more sensitive to noise.

Table 3. The values of quality metrics between the reconstructed image and binarized reconstructed unwrapped star image with Goldstein's and QGPU techniques.

\begin{tabular}{cccccccc}
\hline \multicolumn{2}{c}{ Difference Between Reconstructed and Binarized Unwrapped Reconstructed Star Image } \\
\hline & \multicolumn{2}{c}{ Goldstein's Technique } & \multicolumn{3}{c}{ QGPU Technique } \\
\hline Number of Epochs & MAE & MSE & SSIM & MAE & MSE & SSIM \\
\hline 1000 epochs & 0.0708 & 0.0210 & 0.0401 & 0.0718 & 0.0234 & 0.0412 \\
$\mathbf{2 0 0 0}$ epochs & 0.0707 & 0.0209 & 0.0667 & 0.0697 & 0.0221 & 0.0585 \\
$\mathbf{3 0 0 0}$ epochs & 0.0708 & 0.0210 & 0.0694 & 0.0689 & 0.0216 & 0.0641 \\
$\mathbf{4 0 0 0}$ epochs & 0.0705 & 0.0209 & 0.0704 & 0.0690 & 0.0215 & 0.0660 \\
$\mathbf{5 0 0 0}$ epochs & 0.0708 & 0.0209 & 0.0913 & 0.0680 & 0.0210 & 0.0809 \\
& & & & & & & \\
$\mathbf{1 0 0 0 0}$ epochs & 0.0711 & 0.0211 & 0.1114 & 0.0673 & 0.0205 & 0.0910 \\
\hline
\end{tabular}

\section{Conclusions and Recommendations}

In this paper, we presented the task of digital holographic image reconstruction with the use of a binarized genetic algorithm and in addition, investigated the effects of two different types of unwrapping methods for the reconstruction performance. The glass star object is considered for the simulations. The results obtained from the simulations have shown that the crossover and mutation operators used for the BGA, enable to find of the optimal solution and BGA can reconstruct the original image. In addition, the effects of the two unwrapping methods on the reconstruction 
performance are evaluated. The performance of the algorithms is qualified by considering the accuracy of the image between the scanned and reconstructed ones. It can be concluded that BGA can be applied in digital holographic image reconstruction and unwrapping enables the creation of a 3D image with phase information. On the other hand, unwrapping provides better performance in binarized genetic algorithm reconstructed images in terms of quality measurement metrics and visual quality although unwrapping is sensitive to noise. In addition, in line with these results, it can be concluded that one parameter that affects the performance of BGA can be the number of pixels in the image.

\section{Authors' Contributions}

TÖO and GUK designed the structure. GUK carried out the experiments work, in collaboration with TÖO, and the authors wrote up the article together. Both of the authors are the overall supervisor of the study. Both authors read and approved the final manuscript.

\section{Competing Interests}

The authors declare that they have no competing interests.

\section{References}

[1]. Hansen, M. S., Kellman, P., Image Reconstruction: An Overview for Clinicians, Journal of Magnetic Resonance Imaging, 2015, 41(3): 573-585.

[2]. Moon, I., Jaferzadeh, K., Automated Digital Holographic Image Reconstruction with Deep Convolutional Neural Networks, Proc. SPIE 11402, Three-Dimensional Imaging, Visualization, and Display, 2020, 114020A.

[3]. Kugler, M., Goto, Y., Tamura, Y., Kawamura, N., Kobayashi, H., Yokota, T., Iwamoto, C., Ohuchida, K., Hashizume, M., Shimizu, A., and Hontani, H., Robust 3D Image Reconstruction of Pancreatic Cancer Tumors From Histopathological Images with Different Stains and Its Quantitative Performance Evaluation, International Journal for Computer Assisted Radiology and Surgery, 2019, 14(12): 2047-2055.

[4]. Kawamura, N., Yokota, T., Hontani, H., Sakata, M., and Kimura, Y., Parametric PET Image Reconstruction Viaregional Spatial Bases and Pharmacokinetic Time Activity Model, Entropy, 2017, 19(629): 1-20.

[5]. Rusdi, N. A., Yahya, Z. R., Roslan, N., and Azman Wan Muhamad, W. Z., Reconstruction of Medical Images Using Artificial Bee Colony Algorithm, Mathematical Problems in Engineering, 2018, 2018: 1-7.

[6]. S., Mirjalili, J., Song Dong, A. S., Sadiq, and H., Faris, Genetic Algorithm: Theory, Literature Review, and Application in Image Reconstruction, In: Mirjalili S., Song Dong J., Lewis A. (eds) Nature-Inspired Optimizers. Studies in Computational Intelligence, 811, Springer, Cham, 2020.

[7]. Türken, T., Pala, T., Modeling and Optimization of Sour Cherry Juice Antioxidant Activity by Using Response Surface Methodology and Genetic Algorithm, El-Cezeri Journal of Science and Engineering, 2016, 3(2): 238-247.

[8]. Li, X., Jiang, T., and Evans, D. J., Medical Image Reconstruction Using a Multi-Objective Genetic Local Search Algorithm, International Journal of Computer Mathematics, 2000, 74(3): 301-314.

[9]. Qureshi, S. A., Mirza, S. M., and Arif, M., A Hybrid Continuous Genetic Algorithm for Parallel-Ray Transmission Tomography Image Reconstruction, Journal of Biomedical Informatics, 2006, 1-10. 
[10]. Majeed, A., Mt Piah, A. R., Image Reconstruction Using Rational Ball Interpolant and Genetic Algorithm, Applied Mathematical Sciences, 2014, 8(74): 3683-3692.

[11]. Gray, C. C., Al-Maliki, S. F., and Vidal, F. P., Data Exploration in Evolutionary Reconstruction of PET Images, Genetic Programming and Evolvable Machines, 2018, 19: 391-419.

[12]. Bourgeat, B., Fripp, J., Stanwell, P., and Ramadan, S., MR Image Segmentation of the Knee Bone Using Phase Information, Medical Image Analysis, 2007, 11(4): 325-335.

[13]. Bioucas-Dias, J. S., Valadao, G., Phase Unwrapping: A New Max-flow/min-cut Based Approach, IEEE International Conference on Image Processing, 2005, 1-4.

[14]. Abdul-Rahman, H. S., Gdeisat, M. A., Burton, D. R., Lalor, M. J., Lilley, F., and Moore, C. J., Fast and Robust Three-dimensional Best Path Phase Unwrapping Algorithm, Applied Optics, 2007, 46(26): 6623-6635.

[15]. Hubig, M., Suchandt, S., and Adam, N., A Class of Solution-invariant Transformations of Cost Functions for Minimum Cost Flow Phase Unwrapping, Journal of the Optical Society of America, 2004, 21(10): 1975-87.

[16]. Su, X., Chen, W., Reliability-guided Phase Unwrapping Algorithm: A Review, Optics and Lasers in Engineering, 2004, 42(3): 245-61.

[17]. Diane, N. H., Kim, M. A., Teitell, J. R., and Zangle, T. A., Hybrid Random Walk-linear Discriminant Analysis Method for Unwrapping Quantitative Phase Microscopy Images of Biological Samples, Journal of Biomedical Optics, 2015, 20(11): 111211.

[18]. Zappa, E., Busca, G., Comparison of Eight Unwrapping Algorithms Applied to FourierTransform Profilometry, Optics and Lasers in Engineering, 2008, 46(2): 106-116.

[19]. Wei, H., Ling, X., and Feng, L., Sparse-representation-based Direct Minimum Lp-norm Algorithm for MRI Phase Unwrapping, Computational and Mathematical Methods in Medicine, 2014, 2014: 1-11.

[20]. Z., Michalewicz, Genetic Algorithms + Data Structure $=$ Evolution Programs, AI Series Springer-Verlag, 1994.

[21]. D. E., Goldberg, Genetic Algorithms in Search, Optimization, and Machine Learning, Addison-Wesley, Reading, Mass, 1989.

[22]. M., Mitchell, An Introduction to Genetic Algorithms, MIT Press, Cambridge, MA, 1996.

[23]. Abdul-Rahman, H. S., Gdeisat, M. A., Burton, D. R., and Lalor, M. J., Three Dimensional Phase Unwrapping Algorithms: A Comparison, Proceedings of Photon06 Conference, 2006, $1-12$.

[24]. D. C., Ghiglia, M. D., Pritt, Two-Dimensional Phase Unwrapping, Wiley, 1998.

[25]. Ghiglia, D. C., Mastin, G. A., and Romero, L. A., Cellular Automata Method for Phase Unwrapping, Journal of the Optical Society of America, 1987, 4(1): 267-80.

[26]. Goldstein, R. M., Zebker, H. A., and Werner, C. L., Satellite Radar Interferometry: TwoDimensional Phase Unwrapping, Radio Science, 1988, 23(4): 713-20.

[27]. Pellizzari, C. J., Phase Unwrapping in the Presence of Strong Turbulence, Master of Science, Air Force Institute of Technology Air University, 2010.

[28]. Onur, T. O., Ustabas Kaya, G., and Kaya, C., Phase Shifted-Lateral Shearing Digital Holographic Microscopy Imaging for Early Diagnosis of Cysts in Soft Tissue-Mimicking Phantom, Applied Physics B, 2021, 127(61): 1-13.

[29]. Sara, U., Akter, M., and Uddin, M., Image Quality Assessment Through FSIM, SSIM, MSE and PSNR-A Comparative Study, Journal of Computer and Communications, 2019, 7(3): 818. 